\title{
A Trauma-Informed Approach to Assessment, Case Conceptualization, and Treatment Planning for Youth Exposed to Intimate Partner Violence
}

\author{
Damion J. Grasso
}

Published online: 28 January 2022

(c) National Register of Health Service Psychologists 2021

\begin{abstract}
Children's exposure to intimate partner violence (IPV) is a prevalent public health problem that can result in serious mental health impairments, including traumatic stress. These can emerge early and persist across development. IPV early in life has also been described as a "gateway exposure" to other forms of adversity and trauma. Children and families impacted by IPV have complex needs that complicate assessment and intervention. This paper highlights these issues and reviews best practices in assessment, case conceptualization, and treatment planning as they pertain to the treatment of IPV-exposed children. A case vignette illustrates the complex nature of IPV and application of best practices by telling the story of Isaiah, a 13-year-old boy with an extensive history of IPV exposure and co-occurring adversity and trauma.
\end{abstract}

Keywords Intimate partner violence $\cdot$ IPV $\cdot$ PTSD $\cdot$ Adverse childhood experience $\cdot$ Trauma

\section{Clinical Vignette-Isaiah}

Isaiah, a 13-year-old boy, is referred for mental health services after a child protective services (CPS) investigation substantiated emotional neglect and identified intimate partner violence (IPV) in the home. He lives with his biological mother, Sandra, and Sandra's partner of three years, Joseph. Sandra and Joseph have two children who also live with Isaiah: 2-year-old Dimitri and 9-month-old Juliana. Isaiah's biological father, George, is not currently in contact with Isaiah.

Although Joseph and Sandra would historically engage in loud arguments that would occasionally involve slammed doors and broken furniture, the conflicts did not become physical until the COVID-19 pandemic. Joseph was laid off and Sandra lost work hours, making it hard to cover the bills. Isaiah's school went virtual and childcare became unavailable. Sandra and Joseph struggled to effectively parent the children, especially Isaiah, whose behavior had become more disruptive and who could not engage in remote learning. The increased stress and stay-at-home orders led both Sandra and Joseph to start using substances again.

During this time, arguments increased in intensity to include physical altercations. During one heated argument, when Sandra and Joseph were both intoxicated, Sandra threw a shoe at Joseph, which hit his nose. In response, he became irate and threatened to kill Sandra. When Joseph advanced toward Sandra, Isaiah got in the way and was shoved, causing him to fall backwards into a piece of furniture. He managed to call 911 . The fighting had already subsided when the police arrived. Both Sandra and Joseph were implicated. Police called CPS and all children were temporarily placed into foster care. Isaiah was separated from his siblings, who were placed in a different foster home that only accepted infants and young children.

This is not the first time CPS had been involved. Isaiah was placed into foster care on two separate occasions when he was 2 years old and again when he was 6 years old. Both involved substance use and IPV - this time perpetrated by Isaiah's birthfather, George. George became abusive when Sandra was pregnant with Isaiah and this continued into Isaiah's early childhood. The abuse led to police intervention when Isaiah was 2 years old. George and Sandra were under the influence of substances and got into an argument in which George hit Sandra. CPS substantiated emotional neglect but did not remove Isaiah from the home.

The IPV escalated over the years to the point at which George had socially isolated Sandra and exerted complete control over all aspects of her life. George would threaten to take Isaiah away and sometimes to kill the family pet Chihuahua. The physical violence was also becoming quite intense, for both Sandra and 
Isaiah. George would beat Sandra a few times a week and give Isaiah excessive spankings. George was also sexually violent toward Sandra and would assault her, including times when Isaiah was in the room. Isaiah would become highly distressed, cover his face, and cry while this was happening.

On one occasion, George nearly killed Sandra when he intercepted messages on her phone that she intended to leave the relationship. He punched Sandra in the face and strangled her until she temporarily lost consciousness. Isaiah, then 6 years old, jumped on top of George and was thrown against a wall, hitting his head hard enough to result in a concussion. George left abruptly and Isaiah had to rouse Sandra, who contacted police. CPS was contacted and Isaiah was placed into foster care.

Isaiah's foster placement lasted almost a year. He had supervised visits with his mother, who had eventually followed through with substance use treatment. With the help of a domestic violence advocate, she was no longer with George. Unfortunately, Isaiah's foster home did not prevent further victimization. There were several other children in the home and one of the adolescents in the home sexually assaulted Isaiah on a number of occasions without the foster parents knowing. When this was finally discovered, Isaiah was pulled from the home and placed into a different home until being reunified with Sandra.

Sandra started seeing Joseph when Isaiah was about 9 years old and shortly thereafter gave birth to his brother Dimitri, followed by his sister Juliana. Prepandemic, things were going okay. Joseph had a job at a restaurant and Sandra was working part-time as a house cleaner. Sandra and Joseph would often engage in loud arguments, but only seldom did they resort to anything physical, and never anything to cause injury. While Joseph and Isaiah's relationship was at times rocky, they got along okay most of the time; however, Joseph took more responsibility for parenting his birth children than he did Isaiah.

After the incident when Isaiah called the police, he was placed into foster care where he struggled emotionally and behaviorally. He was able to continue with his current school, which had just started to provide hybrid in-person and remote learning options. However, just a month into his placement, Isaiah had an issue at school. His teacher was frustrated that Isaiah had his head down on the desk and was not paying attention. After trying to redirect Isaiah without success, he eventually went over and put his hand on his shoulder to get his attention. That's when Isaiah sprung from the desk, knocked it over, and threw a punch at his teacher.

\section{Clinical Challenge}

Intimate partner violence (IPV) has been considered a "gateway exposure" to other forms of childhood adversities and can lead to a plethora of stress-relevant mental health impairments that can span multiple diagnostic categories (Grasso, 2020). Two significant challenges exist for children exposed to IPV. First, too many of these children are unidentified as needing intervention, both to prevent subsequent exposure to adversity and to address emerging stressrelated psychopathology. Second, when identified as in need of services, many of these children are not connected to appropriate mental health services, nor are the complex circumstances of IPV adequately considered in the delivery of mental health treatment and adjunct services. The remainder of this article elaborates on these challenges and discusses recommendations for more effectively engaging and supporting IPV-exposed children, referring to the case of Isaiah for illustration.

\section{Intimate Partner Violence-Not Just a Partner Problem}

IPV is more than a partner problem, it is a family problem. In fact, it is a community problem. IPV is pervasive and affects at least 1 out of 5 children in the United States (Hamby et al., 2011; Turner et al., 2016). The majority of households with known IPV contain children, many of them young children who are proximally bound to the caregiving environment. The majority of victims receiving domestic violence shelter services are caregivers (National Network to End Domestic Violence, 2021). More than a third of domestic violence-related arrests involve children who are directly present (Reaves, 2017). Studies that conduct thorough reviews of case records report that the majority of children involved with child protective services have documented IPV exposure in their lifetime (Grasso et al., 2019). Further, more than half of older children and adolescents involved with juvenile justice services have experienced IPV at some point in their lives (Ford et al., 2013b). In effect, IPV is a public health crisis that imposes significant risk of mental health impairment that can emerge early and cascade across development-and across generations.

\section{The Pandemic Has Exacerbated IPV}

Research published since the pandemic has provided evidence that pandemic-related stressors combined with unintended consequences of policies and practices implemented 
to reduce virus spread have exacerbated IPV (Grasso et al., 2021; Holmes et al., 2020). Survey research has revealed that 1 in 5 individuals have experienced an increase in verbal or physical conflict with a partner during the pandemic (Grasso et al., 2021), which aligns with an uptick in IPVrelated arrests (Boserup et al., 2020). For some IPV victims, the pandemic may have been the "tipping point" for physical conflict to occur. Stay-at-home orders have reduced opportunities for respite and help-seeking among victims, with a 50\% reduction in hotline calls over the pandemic (Evans et al., 2020) despite a paradoxical increase in emergency shelter utilization-with many domestic violence shelter agencies reporting well over 100\% capacity (Connecticut Coalition Against Domestic Violence, n.d.). In a similar manner, school closures, interrupted healthcare, and transition to remote services have meant fewer opportunities for child-serving professionals to interact with and identify IPV and adversity-exposed children, with a paradoxical reduction in mandated CPS reports despite increased hospitalizations attributed to maltreatment (Nguyen, 2021; Swedo et al., 2020). Not surprisingly, these increases in violence exposure among children seem to correspond with the surge of mental health impairment and suicidal behavior reported across the country in the later phase of the pandemic.

\section{IPV—the Gateway Exposure}

It is well-established that IPV often co-occurs with other forms of childhood adversity, with most children exposed to IPV also experiencing direct forms of child emotional and physical abuse (Turner et al., 2017). For example, it is not uncommon for IPV offenders to behave toward their children as they do their partners. This violent behavior among IPV offenders can include non-optimal and harsh parenting that is sometimes reported by victimized caregivers. Furthermore, caregivers, who are IPV victims, may be depleted of the personal and social resources necessary for optimal parenting, further contributing to neglect or related childhood adversity (Grasso et al., 2016b; Pu \& Rodriguez, 2021). Many children exposed to IPV are also poly-victims, with cumulative exposure to adversity exponentially increasing risk for subsequent exposure to adversity and trauma, as well as serious mental health impairments (Finkelhor et al., 2009a). There is also evidence that IPV-associated polyvictimization in early childhood is predictive of persistent poly-victimization across developmental periods (Finkelhor et al., 2007; Turner et al., 2017). Notably, a study using data from the National Child Traumatic Stress Network (NCTSN) Core Data Set demonstrated that $87 \%$ of a subgroup of 0 to 5-year-old poly-victims with IPV exposure went on to experience new adversity that characterized poly-victimization in middle childhood, with $74 \%$ of these youth also experiencing poly-victimization in adolescence (Dierkhising et al., 2019; Grasso et al., 2016a). In this study and others, poly-victimized youth at any developmental period were significantly more likely to have diagnosable mental health disorders and serious impairments in functioning. These data underscore the pernicious nature of IPV and how it can contribute to poly-victimization and serious implications for children's development, with the possibility for disruptions in the attainment of vital developmental competencies and emergence of mental health impairment. These data also reflect our overall failure as preventionists and interventionists to interrupt the persistent and pervasive nature of violence exposure and its repercussions.

In what we have learned about Isaiah's history of exposure to IPV and adversity in the opening vignette, it is evident that he would meet our definition of poly-victim, having experienced numerous types of adversities in multiple contexts and across the entirety of his young development. Isaiah's exposure to IPV came early in life and was severe, with incidents in which he would attempt to intervene to stop the violence, sometimes getting hurt in the process. In addition to direct forms of emotional and physical abuse, Isaiah experienced forms of deprivation and neglect, lacking stable and nurturing caregiving because of parental substance abuse and ongoing violence. These circumstances led to CPS involvement and foster care, which opened the door for sexual assault by the older peer, loss of contact with his siblings, and repeat maltreatment after reunification. Except for school, there was little respite for Isaiah — and even that disappeared when schools moved to remote learning during the COVID-19 pandemic. Isaiah was stuck and, up to this point, the system had not protected him.

\section{Isaiah's Trauma History Assessment}

After Isaiah's school incident he was referred to a community-based mental health agency specializing in traumainformed care and scheduled for an intake. Previous records indicated a history of Attention-Deficit Hyperactivity Disorder (ADHD) diagnosed and treated by his pediatrician and known to the school. He had never been assessed for other forms of mental health impairment.

Isaiah was initially resistant to talking with the psychologist and provided only one-word responses. The psychologist spent some time with him before getting into questions about symptoms. The psychologists showed Isaiah his office basketball hoop and threw him the Nerf basketball. Isaiah took some shots. This helped to establish some rapport. The psychologist explained that he was interested in learning more about the types of experiences Isaiah has had and how this makes him feel now. The psychologist explained that what they talked about would be confidential within certain 
limits; however, also explained that if he learned that Isaiah was being hurt now that he may need to tell someone who could help him. The psychologist used a validated trauma exposure inventory to ask Isaiah about his experiences. He explained that Isaiah would not have to provide him with details about what happened, just whether they happened or not. Isaiah endorsed experiences of witnessing IPV and physical abuse, but withheld information about the sexual assault. The psychologist knew about the sexual assault because he had reviewed Isaiah's CPS records. He went back to the question about sexual assault and told Isaiah, "I wanted to go back to this question of whether someone touched your private sexual body parts or made you touch their body parts because I had learned from your CPS caseworker that this may have happened in one of your foster homes six years ago. Again, I don't need you to tell me details about what happened, but I'd like to hear from you whether this happened or not."

\section{Tips for Trauma Assessment}

The extension of the vignette with Isaiah was intended to illustrate key components of trauma assessment with children exposed to IPV. First, given that IPV-exposed children typically experience other forms of co-occurring adversities, psychologists should look beyond IPV exposure to obtain a comprehensive history of the child's exposure to adversity and trauma using one of many available validated instruments. This should be accomplished using multiple sources, including information from child protective services, school personnel, past mental health providers, caregivers, and child self-report. There are many reasons why information may be missing or discordant across sources (e.g., Isaiah withholding information about the sexual assault or caregivers' worry about CPS involvement).

Second, psychologists should consider the optimal timing for administration of a trauma history inventory. Obtaining valid information necessitates a good working rapport with the youth and a sense of safety. Assessing trauma history when the child is in crisis, for example, will not yield valid information.

Third, psychologists should be transparent with the child (and parent) about how the information obtained will and will not be used. Explain any limits to confidentiality, including the potential need to make a mandated report. Emphasize that the intention is to use this information to determine how best to help the child.

Fourth, psychologists should be non-judgmental and avoid making assumptions about how the child perceives their experiences, including perceptions of perpetrators of violence (e.g., it is not uncommon for children to align with an offending parent). Also, in many cases, offending parents resume caregiving or remain a part of the child's life.

Fifth, psychologists should not fear asking questions about trauma. Asking questions does not "re-traumatize" the child, as is often the misconception. Rather, it is a means to getting the child help. Know that the child (or parent) may become uncomfortable or distressed, and this is okay. Be mindful of their reactions and ensure that support is available should the child (or parent) need it. Make explicit the option to talk to and seek support from you during or after completion.

Sixth, psychologists should explain to the child (and parent) that they need not provide extensive detail about any specific trauma exposure, but that the goal is to broadly understand what happened. Many children are not ready to narrate or process the trauma, which may be a goal later in treatment. The caveat here is if there is a necessity to obtain sufficient information in order to make a mandated report of suspected child abuse or neglect.

Finally, if there is knowledge of verified trauma exposure that the child denies or fails to report (e.g., Isaiah's sexual assault), psychologists might consider gently probing a second time, acknowledging where the conflicting information was obtained.

\section{Isaiah's Symptom Assessment}

After assessing Isaiah's trauma history, the health service psychologist used validated symptom rating scales to assess a range of mental health impairments, including posttraumatic stress disorder (PTSD). The psychologist read items aloud to Isaiah, who had difficulty reading, and asked him to provide a rating for reach. Isaiah endorsed symptoms characteristic of posttraumatic stress, which included having frequent thoughts and memories about IPV, trouble sleeping and bad dreams, having negative thoughts about himself, feeling irritable and quick to anger, feeling sad for no reason, and feeling like he is always on "high alert." According to the rating scales, Isaiah exceeded the clinical threshold for posttraumatic stress and depressive symptoms. The psychologist used a semi-structured instrument to determine that Isaiah indeed met criteria for PTSD and that the depressive symptoms were associated with the trauma. Because Isaiah's trauma exposure began shortly after birth and extended across his development, the psychologist was not able to differentiate functioning before and after trauma exposure, as many PTSD symptom scales attempt to do. Rather, as best he could, the psychologist assessed whether each symptom was associated with trauma exposure.

The psychologist was also successful engaging and interviewing Sandra, Isaiah's mother, who was seeing Isaiah weekly in supervised visits. She provided useful context 
around the IPV and elaborated on her family's troubled history. Sandra described Isaiah as being "a handful" and a highly sensitive kid who was quick to react, even to the smallest of things. However, she also described him as a "sweet" kid who "looked out" for her and his siblings-and more than children should have to do. Sandra had separated from Joseph for now, but continued to have contact with him. She still loved Joseph and insisted that he was not the same type of person as George. Sandra once again began substance abuse treatment. Joseph was referred to a fatherfocused intervention for IPV offenders called Fathers for Change, which aims to enhance emotion regulation and interpersonal functioning, thereby reducing aggression and violent behavior. He had supervised visitation with the younger children, but had not yet communicated with Isaiah.

Isaiah's foster mother was present during the intake and completed a broad-based measure of internalizing and externalizing behavior, which revealed elevated scores on observable behavior problems such as impulsivity, oppositionality, and irritability. She also endorsed symptoms of hyperarousal on an assessment of PTSD symptoms. Even though Isaiah's foster mother only knew him for a few months, she noted significant difficulties regulating his emotions. She explained that even something mildly stressful could disrupt Isaiah for an entire day and that he just could not "get himself back together." This was especially true when there were interpersonal stressors, such as when a peer would make a hurtful comment about him.

\section{Consequences of IPV Exposure and Adversity}

IPV and associated adversity can interrupt children's attainment of core competencies, which suggests that it can differentially impact children across development. In early childhood, children are bound to the caregiving environment where developmental competencies are facilitated by their growing relationships with caregivers, with whom they engage in early emotion socialization-learning to identify and reciprocate emotional expression. With a nurturing relationship, infants and young children feel safe to explore their environment and engage in experiential learning, which helps to facilitate motor and cognitive skills. In a harsh and unpredictable environment, young children may not have a secure bond with a caregiver. The caregiver may be emotionally unavailable or may vacillate between nurturing behavior and behavior that conveys danger or threat. In this type of environment, young children's brains are adapting to anticipate, prevent, or protect themselves against potential or actual danger, with fewer resources to attain developmental competencies (Dierkhising et al., 2019).
This early childhood exposure to adversity can have negative implications for middle childhood, where children are spending more time outside of the home. In middle childhood, children are expected to develop healthy peer and adult relationships, regulate emotions, and engage in behaviors to function effectively in school and other settings. School-age children who are exposed to IPV and associated adversity at home must juggle these new academic and school demands with the demands of the home environment. At home, youth in middle school may be protecting a caregiver or siblings, anticipating and protecting oneself from harsh parenting or maltreatment, or compensating for the lack of basic needs or supportive resources at home. Notably, behaviors that may be adaptive in terms of keeping children safe in a violent home environment, such as hypervigilance and physical defensiveness, are seen as highly problematic in school settings. These children are also at higher risk than their nonexposed peers for repeat victimization and exposure to new forms of adversity that can happen outside of the home given greater opportunities for peer victimization, victimization by non-familial adults, witnessing violence in the community, and engaging in risky behavior that may lead to injury (Dierkhising et al., 2019; Finkelhor et al., 2007).

Not surprisingly, failed competencies in early and middle childhood can make adolescence particularly challenging. Adolescence defines a period of greater independence when youth are expected to make healthy decisions, avert risk, exhibit effective self-regulation skills, establish a sexual identity, and continue to develop and maintain healthy relationships, including intimate relationships. Youth without the resources to navigate these challenges are more likely to be those who make poorer decisions, engage in risky behavior, appear dysregulated, either struggle to develop a self-identity or embrace an unhealthy identity, and engage in unhealthy relationships, including the potential for intimate partner and sexual violence. Because development is cumulative, with each developmental stage building on previous attainments, perturbations along the way contribute to serious downstream consequences (Dierkhising et al., 2019; Ford et al., 2013a; Grasso et al., 2016a).

At every stage of development for youth exposed to IPV and adversity are greater risks for developing a host of mental health impairments, with cumulative exposure increasing in a dose-response manner (Finkelhor et al., 2009b; Grasso, 2020). Posttraumatic stress is one of many possible impairments for children that is defined by four symptom clusters tied to the trauma memory. Exposure to IPV, as well as cooccurring violence directed at the child, meets DSM-5 criteria for a PTSD qualifying trauma in that it involves exposure to actual or threatened death or serious injury experienced directly, as a witness, or learning that the event happened to close family member or loved one. Importantly, adversities that commonly co-occur with IPV that do not meet 
criteria for trauma nonetheless can exacerbate symptoms and impair functioning. Further, it is essential to establish a comprehensive conceptualization of a child's history of trauma and adversity for understanding symptomatology and guiding and facilitating treatment. Isaiah has a complicated history of exposure. Any one or more of his exposures may be associated with symptoms or impairment and may have implications for his progress in treatment.

From his intake, it appears that Isaiah shows evidence of symptoms from all four of the clusters that make up the PTSD diagnosis. Characteristic of Criterion B "Intrusive Symptoms," Isaiah reported frequent thoughts and memories about the IPV that interfered with his ability to focus. These elicited psychological distress and physiological reactions. Isaiah would later also endorse intrusive thoughts and nightmares about the sexual assaults he experienced in foster care. Isaiah also drew connections between his sexual assault and the times he witnessed his father, George, sexually assault his mother. He remembered how powerless she was in those moments and how fearful he felt for both of them. It would also be revealed that Isaiah would avoid any thoughts or physical sensations that reminded him of the sexual assaults. This would include seeing himself naked in the shower, as well as times when he would become sexually aroused, which was happening more frequently for him as he entered adolescence. These symptoms fall into Criterion C "Avoidance."

Relatedly, Isaiah felt a lot of guilt around what happened and blamed himself for not being able to protect himself during the assaults. This theme dovetailed with his blaming himself for not being able to protect his mother from George and Joseph. In effect, Isaiah felt a sense of incompetence and guilt. These symptoms are part of Criterion D "Negative Alterations in Cognitions and Mood." Other symptoms in this cluster that Isaiah endorsed included experiencing negative emotions that "would not go away" and trouble experiencing positive emotions. He also felt detached from other people and had exaggerated negative expectations of others. He claimed not to trust anyone.

Finally, Isaiah was experiencing symptoms in Cluster E "Alterations in Arousal and Reactivity," which included feeling chronically irritable and quick to anger and like he was always on "high alert"-looking out for danger when there wasn't any. This symptom cluster directly relates to the incident Isaiah had in school when the teacher put his hand on Isaiah's shoulder. What the teacher did not know was that Isaiah was experiencing intrusive thoughts that were triggered by another youth in the classroom who resembled the boy who had sexually assaulted him. In putting his head down, it appeared to the teacher that Isaiah was noncompliant and unwilling to engage in class. The teacher did not know about Isaiah's history and had never received training in trauma-informed care or how to identify traumatic stress symptoms. Naturally, the teacher took a more punitive perspective.

Not surprisingly, the teacher touching Isaiah's shoulder triggered an aggressive reaction from Isaiah. Isaiah was very worked up and it took a long time for Isaiah to calm down. The school resource officer had to partially restrain him. Isaiah's difficulty re-regulating himself is certainly characteristic of PTSD, but also may reflect severe disruption in core selfregulatory capacities that is characteristic of the proposed developmental trauma disorder or complex PTSD. This presentation has been described as "PTSD with extra caffeine." Youth who present with this type of profound impairment are those who have experienced poly-victimization across developmental periods and more complex forms of interpersonal trauma. Here, too, this knowledge is important for treatment planning for Isaiah and has implications for the work he will do in session.

\section{Tips for Clinical Assessment and Case Conceptualization}

The extension of Isaiah's story in the previous section illustrated key components of symptom assessment and case conceptualization with children exposed to IPV. First, similar to assessing the trauma history, psychologists should strive to obtain symptom information from multiple sources and via multiple methods. Children and parents are often discordant on symptom reports, with parents tending to report more overt symptoms and children better at reporting internalizing symptoms.

Second, psychologists should try not to pigeonhole the child's impairment to posttraumatic stress. A common error is to assume children exposed to trauma will only present with PTSD. IPV and trauma-exposed children can present with a range of symptoms and impairments. Psychologists should assess for posttraumatic stress, but also conduct a comprehensive evaluation of other symptoms and impairment using validated tools - ideally those that have been evaluated on the population they are working with.

When assessing PTSD symptoms, psychologists should allow the child to endorse symptoms as being associated with any one or more of the traumatic experiences captured in their trauma history. They should not require that symptoms be specific to an "index trauma" or the perceived "worst event," as this makes it possible to miss symptoms that might be differentially associated with the child's trauma exposures.

\section{Isaiah's Treatment Planning}

The psychologist diagnoses Isaiah with PTSD and comorbid ADHD, by history, and oppositional defiant disorder (ODD). To address symptoms of PTSD he recommends 
that Isaiah receive Trauma-Focused Cognitive Behavioral Therapy (TF-CBT), an evidence-based intervention with two phases that focus on (1) providing psychoeducation and establishing emotion regulation and cognitive coping skills, and (2) trauma narrative development to facilitate therapeutic exposure and trauma memory processing (Cohen et al., 2018). Because Isaiah has had numerous traumatic events his trauma narrative may require multiple sections and may take longer to develop. The psychologist will establish measurable treatment goals and will employ validated methods to monitor Isaiah's symptoms across the course of treatment to demonstrate treatment effectiveness.

During the trauma narrative phase, themes may emerge that will necessitate cognitive-behavioral strategies for challenging unhealthy beliefs about self, others, and the world that stem from his traumatic experiences. For Isaiah, this may include self-blame and guilt having to do with being a victim of sexual assault and witnessing the physical and sexual victimization of his mother. It may also require processing around his own sexuality as an emerging adolescent, distinguishing it from the sexual assault memory, and becoming less reactive to his body and bodily sensations. Another theme that might emerge may pertain to Isaiah's perception of men and what this means for his own identity as a young man. So far, his experience has been with men who respond to interpersonal problems with aggression and violence. However, there may be opportunities for Isaiah's relationship with Joseph to evolve in a positive direction if Sandra and Joseph resume their relationship and Joseph makes progress in his own treatment. Another theme might involve Isaiah's biased perception of others as untrustworthy and having malintent. If he can accept that he has this bias, he can identify when it is activated and correct it to help facilitate his ability to build and maintain interpersonal relationships.

While research suggests better outcomes for children whose caregivers are engaged in TF-CBT and participate in parallel sessions, including a conjoint session where patients share the trauma narrative, Isaiah's caregiving is complicated. His foster mother has only known him for a short period of time and it is not feasible for Sandra to attend sessions. Given these barriers, the psychologist intends to include Isaiah's foster parent in brief weekly check-ins to convey Isaiah's progress in therapy, reinforce strategies for managing unwanted behavior at home, and coach her on supporting Isaiah's processing of trauma, which not only occurs in session, but can happen at home when children share thoughts and feelings with a caregiver. This tends to happen more frequently during the trauma narrative development. The psychologist also plans to explain to Isaiah's foster mother that it is common for children to show a temporary increase in disruptive behavior during the trauma narrative development phase because the trauma memory and emotional triggers are more salient. She may then decide to share this with the school so that they can anticipate the increase in behavior and make plans to provide extra support during this time.

The psychologist also plans to make an effort to connect with Sandra, Isaiah's mother, to update her on Isaiah's progress and discuss ways in which she can support Isaiah's continued recovery and growth. The psychologist anticipates that he will also need to work with Sandra on identifying and addressing issues that may arise when Isaiah is reunified with the family, especially if she and Joseph get back together. A key objective in this case will be to explore and perhaps redefine Isaiah's relationship with Joseph. The psychologist will leave open the possibility that Isaiah can receive additional sessions after the trauma narrative is complete to address some of these emerging issues. Of course, this will depend on the timing of reunification and whether or not Sandra and Joseph reunite.

\section{Tips for Treatment Planning}

This final extension of Isaiah's story illustrated key components of treatment planning with children exposed to IPV and presenting with PTSD symptoms. First, psychologists should integrate the information obtained during the assessment and conceptualization phase to formulate treatment goals with the child (e.g., symptom reduction, improved functioning) and establish methods for measuring progress, including the use of validated instruments for monitoring symptom change.

Second, treatment goals should be matched to an evidence-based intervention that has been shown to be effective with the population they are working with. Psychologists should consider all of the sociocontextual factors that may play a role in the child's successful engagement in treatment and capacity to benefit from treatment modalities. For trauma-specific treatment, psychologists should give careful thought to which traumatic experiences may become the focus of the trauma narrative or retelling and how their formulation of the child's trauma history will be incorporated in the child's cognitive processing (e.g., emergent themes and unhealthy cognitions).

Third, psychologists should always consider options for engaging caregivers in the child's treatment when it is appropriate to do so, as this will help to support the child's progress in their home environment. Finally, psychologists should anticipate potential setbacks or new issues that may emerge because of changes in the child's living situation or family circumstances and make a plan to address these. 


\section{Concluding Thoughts}

This article introduced Isaiah, a 13-year-old boy with an extensive history of IPV exposure, adversity, and trauma. Along the way, we learned about unique circumstances of IPV that influence assessment, case conceptualization, and treatment planning. This was illustrated in Isaiah's story, which involved co-occurring adversity including sexual assault, multiple perpetrators, adverse impacts of the COVID-19 pandemic, changes in caregiving, and symptom manifestations that impacted his functioning at school. We observed how Isaiah's complicated trauma history influenced his engagement in treatment and emergent themes and unhealthy cognitions that served to maintain symptoms and dysfunction. There are several key takeaways: (1) IPV is complex and often co-occurs with other forms of victimization, trauma, and deprivation; (2) assessment of the trauma history should be carefully orchestrated and comprehensive, with information acquired from multiple sources; (3) clinical assessment should focus on both broad-based and traumaspecific symptoms, with information obtained from multiple sources and via multiple methods; (4) case conceptualization and treatment planning should incorporate the child's trauma history, co-occurring adversities, and other sociocontextual factors that may influence treatment engagement and response, including anticipated setbacks or upcoming changes to the child's living situation or circumstances.

\section{References}

Boserup, B., McKenney, M., \& Elkbuli, A. (2020). Alarming trends in US domestic violence during the COVID-19 pandemic. In American Journal of Emergency Medicine (Vol. 0, Issue 0, pp. 2753-2755). W.B. Saunders. https://doi.org/10.1016/j.ajem. 2020.04.077

Cohen, J. A., Deblinger, E., \& Mannarino, A. P. (2018). Traumafocused cognitive behavioral therapy for children and families. Psychotherapy Research, 28(1), 47-57. https://doi.org/10.1080/ 10503307.2016.1208375

Connecticut Coalition Against Domestic Violence. (n.d.). Connecticut Coalition Against Domestic Violence: CT Service Statistics. Retrieved December 1, 2020, from http://www.ctcadv.org/infor mation-about-domestic-violence/statistics/

Dierkhising, C. B., Ford, J. D., Branson, C., Grasso, D. J., \& Lee, R. (2019). Developmental timing of polyvictimization: Continuity, change, and association with adverse outcomes in adolescence. Child Abuse and Neglect, 87(May 2017), 40-50. https://doi.org/ 10.1016/j.chiabu.2018.07.022

Evans, M. L., Lindauer, M., \& Farrell, M. E. (2020). A Pandemic within a Pandemic - Intimate Partner Violence during Covid-19. New England Journal of Medicine, 383(24), 2302-2304. https:// doi.org/10.1056/nejmp2024046

Finkelhor, D., Ormrod, R. K., \& Turner, H. A. (2007). Re-victimization patterns in a national longitudinal sample of children and youth. Child Abuse and Neglect, 31(5), 479-502. https://doi.org/10. 1016/j.chiabu.2006.03.012
Finkelhor, D., Ormrod, R. K., \& Turner, H. A. (2009a). Lifetime assessment of poly-victimization in a national sample of children and youth. Child Abuse and Neglect, 33(7), 403-411. https://doi. org/10.1016/j.chiabu.2008.09.012

Finkelhor, D., Ormrod, R., Turner, H., \& Holt, M. (2009b). Pathways to poly-victimization. Child Maltreatment, 14(4), 316-329. https:// doi.org/10.1177/1077559509347012

Ford, J. D., Grasso, D., Greene, C., Levine, J., Spinazzola, J., \& van der Kolk, B. (2013a). Clinical Significance of a Proposed Developmental Trauma Disorder Diagnosis. The Journal of Clinical Psychiatry, 74(08), 841-849. https://doi.org/10.4088/jcp.12m08030

Ford, J. D., Grasso, D. J., Hawke, J., \& Chapman, J. F. (2013b). Polyvictimization among juvenile justice-involved youths. Child Abuse and Neglect, 37(10), 788-800. https://doi.org/10.1016/j.chiabu. 2013.01.005

Grasso, D. J. (2020). Adverse Childhood Experiences and Traumatic Stress Disorders. In J. G. Beck \& D. M. Sloan (Eds.), Handbook of Traumatic Stress Disorders (2nd Edition) (2nd ed.). Oxford University Press.

Grasso, D. J., Briggs-Gowan, M. J., Carter, A. S., Goldstein, B. L., \& Ford, J. D. (2021). Profiling COVID-related experiences in the United States with the Epidemic-Pandemic Impacts Inventory: Linkages to psychosocial functioning. Brain and Behavior, e02197. https://doi.org/10.1002/BRB3.2197

Grasso, D.J., Dierkhising, C. B., Branson, C. E., Ford, J. D., \& Lee, R. (2016a). Developmental Patterns of Adverse Childhood Experiences and Current Symptoms and Impairment in Youth Referred for Trauma-Specific Services. Journal of Abnormal Child Psychology, 44(5), 871-886. https://doi.org/10.1007/ s10802-015-0086-8

Grasso, D. J., DiVietro, S., Beebe, R., Clough, M., \& Lapidus, G. (2019). Quantifying Severity of Maltreatment, Adversity, and Trauma from Child Protective Services Case Record Files. Journal of Interpersonal Violence. https://doi.org/10.1177/08862 60519847774

Grasso, D. J., Henry, D., Kestler, J., Nieto, R., Wakschlag, L. S., \& Briggs-Gowan, M. J. (2016b). Harsh Parenting as a Potential Mediator of the Association Between Intimate Partner Violence and Child Disruptive Behavior in Families With Young Children. Journal of Interpersonal Violence, 31(11), 2102-2126. https://doi. org/10.1177/0886260515572472

Hamby, S., Finkelhor, D., Turner, H., \& Ormrod, R. (2011). Children's exposure to intimate partner violence and other family violence. Juvenile Justice Bulletin.

Holmes, E. A., O'Connor, R. C., Perry, V. H., Tracey, I., Wessely, S., Arseneault, L., Ballard, C., Christensen, H., Cohen Silver, R., Everall, I., Ford, T., John, A., Kabir, T., King, K., Madan, I., Michie, S., Przybylski, A. K., Shafran, R., Sweeney, A., ... Bullmore, E. (2020). Multidisciplinary research priorities for the COVID-19 pandemic: a call for action for mental health science. The Lancet Psychiatry, 547-560. https://doi.org/10.1016/S22150366(20)30168-1

National Network to End Domestic Violence. (2021). 15th Annual Domestic Violence Counts Report.

Nguyen, L. H. (2021). Calculating the impact of COVID-19 pandemic on child abuse and neglect in the U.S. Child Abuse and Neglect, 118, 105136. https://doi.org/10.1016/j.chiabu.2021.105136

Pu, D. F., \& Rodriguez, C. M. (2021). Spillover and Crossover Effects: Mothers' and Fathers' Intimate Partner Violence, Parent-Child Aggression Risk, and Child Behavior Problems. Child Maltreatment, 26(4), 420-430. https://doi.org/10.1177/1077559520985936

Reaves, B. A. (2017). Police Response to Domestic Violence, 2006-2015.

Swedo, E., Idaikkadar, N., Leemis, R., Dias, T., Radhakrishnan, L., Stein, Z., Chen, M., Agathis, N., \& Holland, K. (2020). Trends in U.S. Emergency Department Visits Related to Suspected or 
Confirmed Child Abuse and Neglect Among Children and Adolescents Aged $<18$ Years Before and During the COVID-19 Pandemic - United States, January 2019-September 2020. MMWR. Morbidity and Mortality Weekly Report, 69(49), 1841-1847. https://doi.org/10.15585/mmwr.mm6949a1

Turner, H. A., Shattuck, A., Finkelhor, D., \& Hamby, S. (2016). Polyvictimization and Youth Violence Exposure Across Contexts. Journal of Adolescent Health, 58(2), 208-214. https://doi.org/ 10.1016/J.JADOHEALTH.2015.09.021

Turner, H. A., Shattuck, A., Finkelhor, D., \& Hamby, S. (2017). Effects of Poly-Victimization on Adolescent Social Support, SelfConcept, and Psychological Distress. Journal of Interpersonal Violence, 32(5), 755-780. https://doi.org/10.1177/0886260515 586376
Damion J. Grasso, PhD, is a licensed clinical psychologist and Associate Professor of Psychiatry and Pediatrics at the University of Connecticut School of Medicine. He earned his PhD in Clinical Psychology from the University of Delaware. His research focuses on biobehavioral mechanisms involved in the relationship between childhood adversity and emergent psychopathology across development. His research also focuses on evidence-based assessment and treatment of trauma-related disorders, with an emphasis on childhood posttraumatic stress disorder (PTSD). Dr. Grasso serves as an Associate Editor of the Journal of Health Services Psychology. 